\title{
Hydrogen permeation behavior in polycrystalline nickel implanted with various elements
}

\author{
R. Nishimura ${ }^{1}$, K. Okitsu ${ }^{1}$, H. Inoue ${ }^{1}$, R. M. Latanision ${ }^{2}$ \\ \& G. K. Hubler ${ }^{3}$ \\ ${ }^{1}$ Osaka Prefecture University, Japan \\ ${ }^{2}$ Massachusetts Institute of Technology, USA \\ ${ }^{3}$ U.S. Naval Research Laboratory, USA
}

\begin{abstract}
The entry and transport of hydrogen in polycrystalline nickel implanted with various elements $(\mathrm{He}, \mathrm{Ar}, \mathrm{B}, \mathrm{P}, \mathrm{S}, \mathrm{Bi}, \mathrm{Ni}, \mathrm{Y}, \mathrm{Pt}, \mathrm{As}, \mathrm{Pb}$ and $\mathrm{Sb}$ ) has been investigated in a fluence range of $1 \times 10^{14}$ to $2 \times 10^{17}$ ions $/ \mathrm{cm}^{2}$ using an electrochemical permeation technique and etching technique, where the elements used are categorized as follows: inert elements ( $\mathrm{He}$ and $\mathrm{Ar}$ ), the substrate element (Ni), metalloids (P, S, Sb and As), a catalytic element (Pt) and the other elements $(\mathrm{Pb}, \mathrm{Bi}, \mathrm{Y}$ and $\mathrm{B})$. It was found that the effective diffusion coefficient of hydrogen and the effective solubility were largely dependent upon fluence and elements in comparison to those obtained from non-implanted nickel. The results obtained were qualitatively explained in terms of gas bubbles and defects generated by implantation, compressive stress, catalytic effect, the formation of amorphous phase and so on.
\end{abstract}

Keywords: hydrogen permeation, ion implantation, fluence, element, hydrogen diffusion coefficient, hydrogen solubility.

\section{Introduction}

Many researchers have investigated the interrelation between hydrogen embrittlement (HE) and metalloid segregation as metalloids may act as preferential grain boundaries in metals and alloys [1-6]. Segregated sites for the absorption of hydrogen may decrease the cohesive strength of the material. 
Ion implantation may be the best method to prepare surfaces for segregation studies without affecting bulk physical or mechanical properties, because any element can be implanted and the concentration of segregated elements may be controlled over several orders of magnitude. In the present paper, the entry and transport of hydrogen in nickel implanted with various elements (12 elements) were investigated to identify effects caused by the process of ion implantation, a catalytic effect, phase and structure of implanted layers and so on. The results obtained were qualitatively explained in terms of gas bubbles and defects generated by implantation, compressive stress, catalytic effect, the formation of amorphous phase and so on.

\section{Experiment}

Strips of Ni270 (99.97\%) were cold rolled, annealed at $1273 \mathrm{~K}$ for $10 \mathrm{~min}$ and then water quenched. Electropolishing of the specimens was performed in an aqueous $60 \% \mathrm{H}_{2} \mathrm{SO}_{4}$ solution (bath voltage $5 \mathrm{~V}$ ) at room temperature using a platinum electrode as the cathode. The specimens with a thickness of $105 \mu \mathrm{m}$ were not coated with palladium.

Table 1: $\quad$ Ion implantation parameters and in range statistics.

\begin{tabular}{lcccc}
\hline Ion & Energy $(\mathrm{keV})$ & $\mathrm{Q}_{\text {fluence }}\left(\mathrm{cm}^{-2}\right)$ & $\mathrm{R}_{\mathrm{p}}(\mathrm{nm})$ & $\Delta \mathrm{R}_{\mathrm{p}}(\mathrm{nm})$ \\
\hline $\mathrm{He}$ & 25 & $1 \times 10^{16}, 1 \times 10^{17}$ & 87 & 14 \\
$\mathrm{~B}$ & 25 & $1 \times 10^{17}, 3 \times 10^{17}$ & 35 & 20 \\
$\mathrm{P}$ & 50 & $1 \times 10^{15} \sim 1 \times 10^{17}$ & 24 & 12 \\
$\mathrm{Ar}$ & 60 & $1 \times 10^{15} \sim 1 \times 10^{17}$ & 24 & 12 \\
$\mathrm{Ni}$ & 90 & $1 \times 10^{14} \sim 1 \times 10^{17}$ & 25 & 12 \\
$\mathrm{As}$ & 110 & $1 \times 10^{16}, 1 \times 10^{17}$ & 26 & 12 \\
$\mathrm{Y}$ & 125 & $1 \times 10^{17}$ & 25 & 12 \\
$\mathrm{Sn}$ & 145 & $1 \times 10^{17}$ & 25 & 10 \\
$\mathrm{Sb}$ & 150 & $1 \times 10^{15} \sim 1 \times 10^{17}$ & 25 & 10 \\
$\mathrm{Pt}$ & 180 & $1 \times 10^{15} \sim 1 \times 10^{16}$ & 25 & 8.6 \\
$\mathrm{~Pb}$ & 180 & $1 \times 10^{15} \sim 1 \times 10^{17}$ & 25 & 8.3 \\
$\mathrm{Bi}$ & 180 & $1 \times 10^{17}$ & 25 & 8.2 \\
\hline
\end{tabular}

The electropolished specimens were implanted on the cathodic side (the side where hydrogen evolution occurs) by clamping the edge of a rectangular $(5 \mathrm{~cm} \mathrm{x}$ $2.5 \mathrm{~cm}$ ) foil along the dimension with razor blade masks. The cryopumped vacuum was kept at pressures between $3 \times 10^{-7}$ and $2 \times 10^{-6}$ Torr and the ion beam current density was held below $1 \mu \mathrm{A} / \mathrm{cm}^{2}$ in order to minimize specimen heating. The ions were implanted at normal incidence to the surface and the beam was raster scanned to produce a uniform fluence measured to better than $\pm 2.0 \%$. The fluences and energies of implantation are given in table 1 , which also shows the calculated projected range $R_{p}$ of implanted ions and the standard deviation $\Delta R_{p}$, where $R_{p}$ was almost constant under the various ion implantation 
conditions with the exception of helium. The elements used are categorized as follows; inert elements (He and Ar), the substrate element (Ni), metalloids ( $\mathrm{P}, \mathrm{S}$, $\mathrm{Sb}$ and $\mathrm{As})$, a catalytic element $(\mathrm{Pt})$ and the other elements $(\mathrm{Pb}, \mathrm{Bi}, \mathrm{Y}$ and $\mathrm{B})$.

The method developed by Devanathan and Stachurski [7] was used for the permeation measurements. The specimens were mounted between the two half-cells, giving a $0.95 \mathrm{~cm}^{2}$ area of exposure. The cathodic and anodic compartments contained $0.05 \mathrm{kmol} / \mathrm{m}^{3} \mathrm{H}_{2} \mathrm{SO}_{4}$ and $0.1 \mathrm{kmol} / \mathrm{m}^{3} \mathrm{NaOH}$ solutions respectively. Both solutions were deaerated with pre-purified nitrogen prior to the experiments. Hydrogen charging in the cathodic compartment was controlled by galvanostatic cathodic polarization with a current density of $1.47 \mathrm{~mA} / \mathrm{cm}^{2}$. The anodic side of the specimens was potentiostatically polarized at $+0.1 \mathrm{~V} / \mathrm{SCE}$. When the anodic current became negligible (less than $10 \mathrm{nA} / \mathrm{cm}^{2}$ ), hydrogen charging was started. All experiments were carried out at $303 \pm 0.1 \mathrm{~K}$. Permeation data were frequently analyzed for $\mathrm{D}_{\text {lag }}$, the diffusion coefficient and $\mathrm{C}_{\mathrm{H}}$, the concentration of hydrogen adsorbed just beneath the surface, which are calculated by using the time lag method [7] as follows:

$$
\mathrm{D}_{\text {lag }}=\mathrm{L}^{2} / 6 \mathrm{t}_{\text {lag }} \text { and } \mathrm{P}_{\infty}=\mathrm{D}_{\text {lag }} \cdot \mathrm{C}_{\mathrm{H}} \cdot \mathrm{F} / \mathrm{L}
$$

where $\mathrm{L}$ is the thickness of the specimens, $\mathrm{t}_{\text {lag }}$ the time of a lag, $\mathrm{P}_{\infty}$ the steady state permeation current density and $F$ the Faraday constant. $D_{\text {lag }}$ and $C_{H}$ of the un-implanted nickel (pure nickel) thus obtained were $3.8 \times 10^{-10} \mathrm{~cm}^{2} / \mathrm{s}$ and $2.5 \mathrm{x}$ $10^{-6} \mathrm{~mol} / \mathrm{cm}^{3}$, respectively. Here, it should be recognized that $\mathrm{D}_{\text {lag }}$ and $\mathrm{C}_{\mathrm{H}}$ for all the implanted nickel samples are taken into consideration to compare with those of the un-implanted nickel samples because of the lack of physical significance of the derived quantities, $\mathrm{D}_{\mathrm{lag}}$ and $\mathrm{C}_{\mathrm{H}}$. In addition, the implantation depth constitutes only about 1 part in 4000 of the total thickness, which means that the diffusion length of hydrogen is almost equal to that in the bulk and hence $\mathrm{D}_{\text {lag }}$ and $\mathrm{C}_{\mathrm{H}}$ for all the implanted nickels are the effective diffusion coefficient and concentration for the entire sample. As described above, we can obtain three parameters from the hydrogen transients $\left(\mathrm{P}_{\infty}, \mathrm{D}_{\text {lag }}\right.$ and $\left.\mathrm{C}_{\mathrm{H}}\right)$.

\section{Results}

\subsection{Substrate element (Ni)}

Fig. 1 shows the hydrogen permeation transients and three parameters $\left(\mathrm{P}_{\infty}, \mathrm{D}_{\text {lag }}\right.$ and $\mathrm{C}_{\mathrm{H}}$ ) of $\mathrm{Ni}$ - implanted nickel with a fluence of $1 \times 10^{14}$ to $1 \times 10^{17} / \mathrm{cm}^{2}$, where the broken line in the figure indicates a typical permeation transient for unimplanted nickel (pure nickel) as a reference. It was found that the steady state permeation current densities $\left(\mathrm{P}_{\infty}\right)$ tended to become larger for nickel implanted with fluences of $1 \times 10^{16}$ and $1 \times 10^{17} / \mathrm{cm}^{2}$ and smaller for nickel implanted with fluences of $1 \times 10^{14}$ and $1 \times 10^{15} / \mathrm{cm}^{2}$ than for un-implanted nickel, even if the difference in membrane thickness shown in the figure is taken into consideration: 
the thinner the membrane thickness, the larger $\mathrm{P}_{\infty}$ is. Correspondingly, $\mathrm{D}_{\text {lag }}$ decreased with increasing fluence, while the fluence dependence of $\mathrm{C}_{\mathrm{H}}$ was the same as that of $\mathrm{P}_{\infty}$.
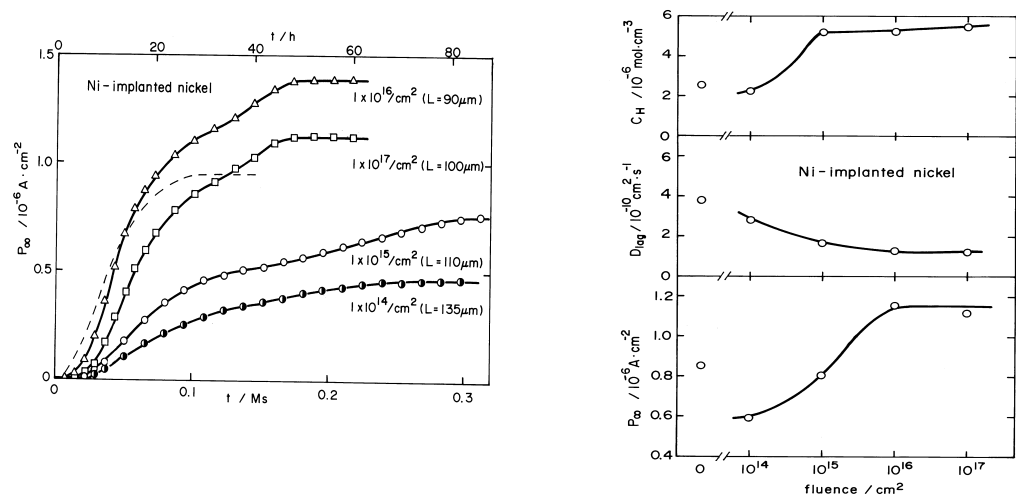

Figure 1: The hydrogen permeation transients and three parameters $\left(\mathrm{P}_{\infty}, \mathrm{D}_{\text {lag }}\right.$ and $\mathrm{C}_{\mathrm{H}}$ ) of $\mathrm{Ni}$ - implanted nickel with a fluence of $1 \times 10^{14}$ to $1 \times 10^{17} / \mathrm{cm}^{2}$, where the broken line in the figure indicates a typical permeation transient for un-implanted nickel.

\subsection{Inert elements (He and $\mathrm{Ar})$}

Fig. 2 shows the hydrogen permeation transients and three parameters $\left(\mathrm{P}_{\infty}, \mathrm{D}_{\text {lag }}\right.$ and $\mathrm{C}_{\mathrm{H}}$ ) of Ar- implanted nickel with a fluence of $1 \times 10^{15}$ to $1 \times 10^{17} / \mathrm{cm}^{2}$, where the broken line in the figure indicates a typical permeation transient for unimplanted nickel. It was evident that the breakthrough time of the transients was larger than that of un-implanted nickel.
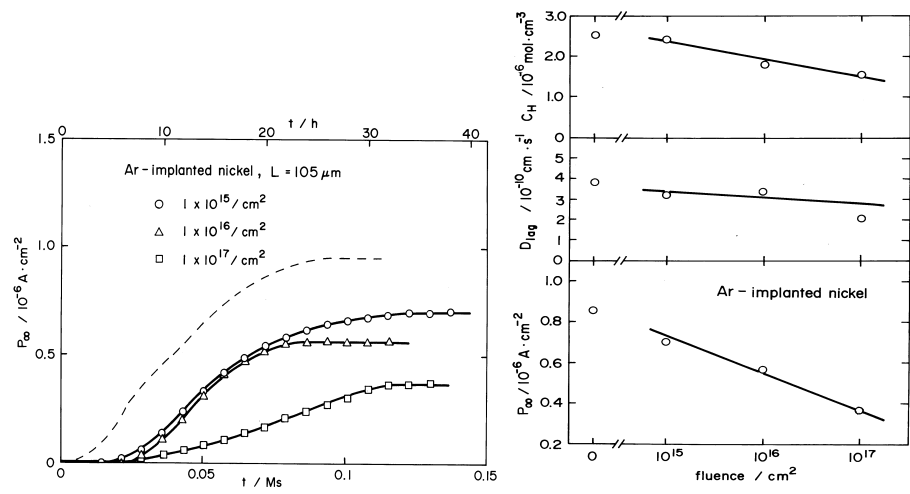

Figure 2: $\quad$ The hydrogen permeation transients and three parameters $\left(\mathrm{P}_{\infty}, \mathrm{D}_{\text {lag }}\right.$ and $\mathrm{C}_{\mathrm{H}}$ ) of Ar- nickel implanted with a fluence of $1 \times 10^{15}$ to $1 \mathrm{x}$ $10^{17} / \mathrm{cm}^{2}$, where the broken line in the figure indicates a typical permeation transient for un-implanted nickel. 
The three parameters of Ar- implanted nickel decreased with increasing fluence and were smaller than those of un-implanted nickel. The fluence dependence of the three parameters was found to be different from that of Ni- implanted nickel. The permeation transients of He- implanted nickel were almost the same behavior as those of Ar- implanted nickel.

\subsection{Metalloids (P, S, Sb and As)}

Fig. 3 shows the hydrogen permeation transients and three parameters $\left(\mathrm{P}_{\infty}, \mathrm{D}_{\text {lag }}\right.$ and $\mathrm{C}_{\mathrm{H}}$ ) of $\mathrm{P}$ - implanted nickel with a fluence of $1 \times 10^{15}$ to $1 \times 10^{17} / \mathrm{cm}^{2}$, where the broken line in the figure indicates a typical permeation transient for un-implanted nickel. Although the breakthrough time and $\mathrm{P}_{\infty}$ tended to increase with the increase in fluence, specifically, for a fluence of $1 \times 10^{17} / \mathrm{cm}^{2}$ the breakthrough time became almost the same as that of un-implanted nickel and $\mathrm{P}_{\infty}$ was much larger than that of un-implanted nickel. The behavior of the three parameters was also found to depend largely upon fluence and to be different from those in Figs. 1 and 2.
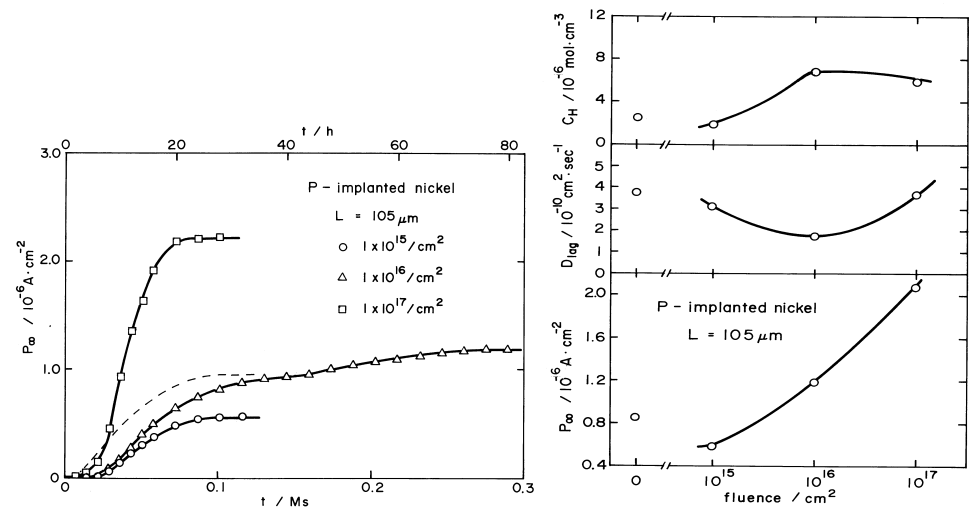

Figure 3: The hydrogen permeation transients and three parameters $\left(\mathrm{P}_{\infty}, \mathrm{D}_{\text {lag }}\right.$ and $\mathrm{C}_{\mathrm{H}}$ ) of $\mathrm{P}$ - implanted nickel with a fluence of $1 \times 10^{15}$ to $1 \times 10^{17} / \mathrm{cm}^{2}$, where the broken line indicates a typical permeation transient for un-implanted nickel.

Fig. 4 shows the hydrogen permeation transients and three parameters $\left(\mathrm{P}_{\infty}\right.$, $D_{\text {lag }}$ and $C_{H}$ ) of S- implanted nickel with a fluence of $1 \times 10^{15}$ to $1 \times 10^{17} / \mathrm{cm}^{2}$, where the broken line in the figure indicates a typical permeation transient for un-implanted nickel. It was found that the breakthrough time decreased with increasing fluence, while $\mathrm{P}_{\infty}$ tended to increase with increasing fluence, but decreased clearly at a fluence of $1 \times 10^{17} / \mathrm{cm}^{2}$. The fluence dependence of the three parameters was different from those in Figs. 1, 2 and 3.

Fig. 5 shows the hydrogen permeation transients of As- implanted nickel with a fluence of $1 \times 10^{16}$ and $1 \times 10^{17} / \mathrm{cm}^{2}$, where the broken line in the figure indicates a typical permeation transient for un-implanted nickel. It was found that the permeation transients were almost the same behavior as those of P- implanted nickel with the same fluences. 

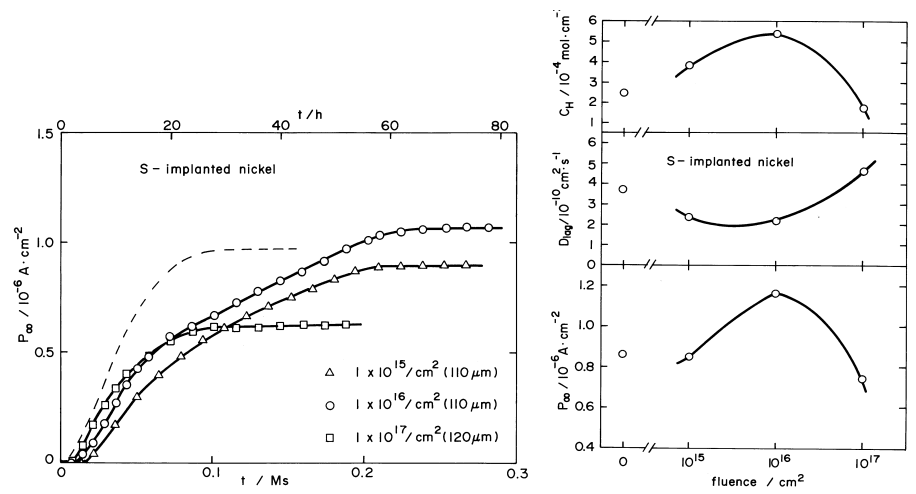

Figure 4: The hydrogen permeation transients and three parameters $\left(\mathrm{P}_{\infty}, \mathrm{D}_{\text {lag }}\right.$ and $\mathrm{C}_{\mathrm{H}}$ ) of $\mathrm{S}$ - implanted nickel with a fluence of $1 \times 10^{15}$ to $1 \times 10^{17} / \mathrm{cm}^{2}$, where the broken line indicates a typical permeation transient for un-implanted nickel.

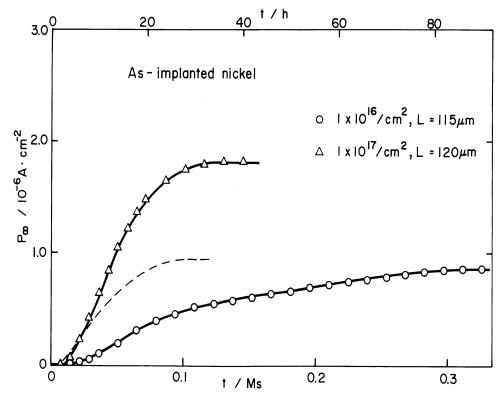

Figure 5: The hydrogen permeation transients of As- implanted nickel with fluences of $1 \times 10^{16}$ and $1 \times 10^{17} / \mathrm{cm}^{2}$, where the broken line indicates a typical permeation transient for un-implanted nickel.

\subsection{Catalytic element (Pt)}

Fig. 6 shows the hydrogen permeation transients and three parameters $\left(\mathrm{P}_{\infty}, \mathrm{D}_{\mathrm{lag}}\right.$ and $\mathrm{C}_{\mathrm{H}}$ ) of Pt- implanted nickel with a fluence of $1 \times 10^{15}$ to $1 \times 10^{16} / \mathrm{cm}^{2}$, where the broken line in the figure indicates a typical permeation transient for un-implanted nickel. The range of fluences for Pt- implanted nickel was only $1 \times 10^{15}$ to $1 \times 10^{16} / \mathrm{cm}^{2}$ because of the difficulty in obtaining high beam currents of platinum ions. The breakthrough time was much longer than for un-implanted nickel and $\mathrm{P}_{\infty}$ was found to increase with increasing fluence. The fluence dependence of the three parameters was similar to that of Ni- implanted nickel.

\subsection{Other elements ( $\mathrm{Pb}, \mathrm{Bi}, \mathrm{Y}$ and $\mathrm{B})$}

Fig. 7 shows the hydrogen permeation transients of $\mathrm{B}-$ and $\mathrm{Bi}-$ implanted with a fluence of $1 \times 10^{17}$ or $3 \times 10^{17} / \mathrm{cm}^{2}$, where the broken line in the figure indicates a typical permeation transient for un-implanted nickel. 

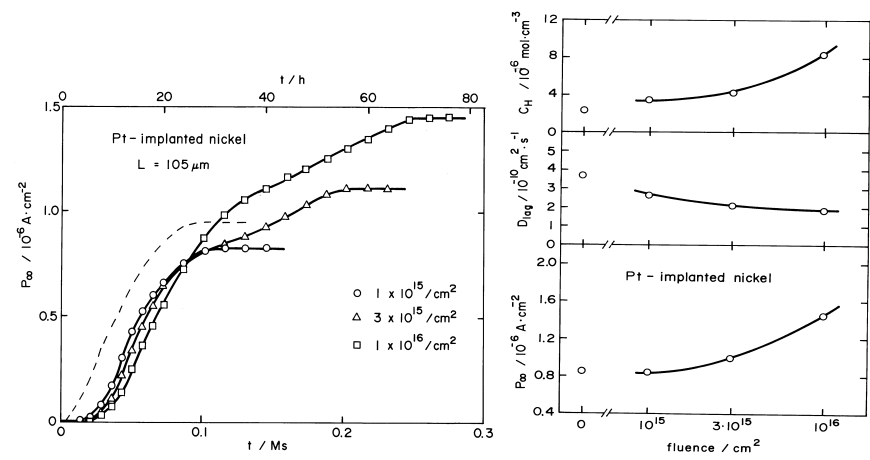

Figure 6: The hydrogen permeation transients and three parameters $\left(\mathrm{P}_{\infty}, \mathrm{D}_{\text {lag }}\right.$ and $\mathrm{C}_{\mathrm{H}}$ ) of $\mathrm{Pt}$ implanted nickel with a fluence of $1 \times 10^{16}$ to $1 \times 10^{17} / \mathrm{cm}^{2}$, where the broken line in the figure indicates a typical permeation transient for un-implanted nickel.
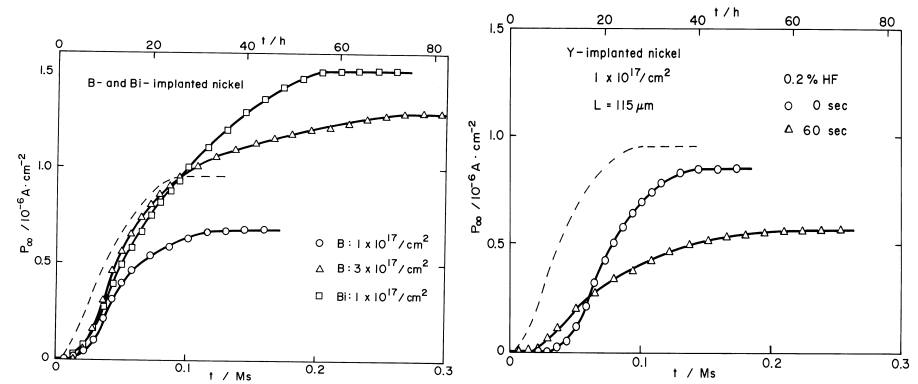

Figure 7: The hydrogen permeation transients of $\mathrm{B}-, \mathrm{Bi}-$ and $\mathrm{Y}$ - implanted nickel with a fluence of $1 \times 10^{16}$ to $3 \times 10^{17} / \mathrm{cm}^{2}$, where the broken lines in the figure indicate a typical permeation transient for unimplanted nickel.

The breakthrough time of these implanted nickels was almost the same, but smaller than that of un-implanted nickel. $\mathrm{P}_{\infty}$ for $\mathrm{Bi}$ - implanted nickel with a fluence of $1 \times 10^{17} / \mathrm{cm}^{2}$ and for B- implanted nickel with $3 \times 10^{17} / \mathrm{cm}^{2}$ were larger than that of un-implanted nickel, but that of B- implanted nickel with $1 \mathrm{x} 10^{17} / \mathrm{cm}^{2}$ was smaller than that of un-implanted nickel. The breakthrough time of $\mathrm{Y}$ - implanted nickel is much longer than that for un-implanted nickel, whereas $\mathrm{P}_{\infty}$ was almost the same as that for un-implanted nickel, although it became smaller by the etching treatment of $60 \mathrm{~s}$. For $\mathrm{Pb}$ - implanted nickel, the breakthrough time was constant and independent of fluence and $\mathrm{P}_{\infty}$ tended to increase with increasing fluence, although $\mathrm{P}_{\infty}$ was larger than that of un-implanted nickel. 


\section{Discussion}

It is well known that shallow and deep traps, compressive stress and occupied interstitial sites are generated by ion implantation 8]. Deep and shallow traps contribute to delay in breakthrough (corresponding to the decrease in $\mathrm{D}_{\text {lag }}$ ), which are observed for almost all the implanted nickels, but lead to the increase in $\mathrm{C}_{\mathrm{H}}$. This is recognized from eq. (1), if $\mathrm{P}_{\infty}$ keeps constant, and is applied to the transient for $\mathrm{Y}$ - implanted nickel. In the case that the shallow traps are dominant, $\mathrm{P}_{\infty}$ increases as well as the increase in $\mathrm{C}_{\mathrm{H}}$, because some part of hydrogen trapped in the shallow traps is released, which is observed in the form of the dual rise time transient as shown for $\mathrm{Ni}$ - and $\mathrm{Pt}$ - implanted nickels with a relatively high fluence in Figs. 1 and 2. On the other hand, the compressive stress leads to the decrease in $\mathrm{P}_{\infty}$ and $\mathrm{C}_{\mathrm{H}}$, since a number of the entry site for hydrogen decreases. This is observed for the transients of almost all implanted nickels with a low fluence of less than $10^{15} / \mathrm{cm}^{2}$, showing the decrease in $\mathrm{P}_{\infty}$ and $\mathrm{C}_{\mathrm{H}}$ and little change in $\mathrm{D}_{\text {lag. }}$. The same effect is caused by the formation of gas bubbles such as He and Ar as shown in Fig. 2 [9].

It is well known that platinum shows a catalytic effect on hydrogen evolution reaction, which means that an amount of the absorbed hydrogen decreases and as a result the decrease in $\mathrm{P}_{\infty}$ and $\mathrm{C}_{\mathrm{H}}$ with little change in $\mathrm{D}_{\text {lag }}$ takes place. However, the transients of Pt- implanted nickels in Fig. 3 cannot support the catalytic effect of platinum. It is confirmed by Rutherford backscattering that a concentration of platinum at the outer layer of the implanted layer in contact with the solution is very low, whereas the maximum platinum concentration becomes about $3 \%$ in the implanted layer at a fluence of $3 \times 10^{16} / \mathrm{cm}^{2}$. This means that the concentration at the outer layer of the implanted layer is important, but not inside. To evaluate this, after the implanted layer was resolved layer by layer by using $0.2 \% \mathrm{HF}$ solution, the transients at various etching times were measured. It was found that the catalytic effect of platinum was observed, that is, the decrease in $\mathrm{P}_{\infty}$ and $\mathrm{C}_{\mathrm{H}}$ with little change in $\mathrm{D}_{\text {lag }}$. On the other hand, arsenic is well known to be a poison for hydrogen evolution reaction, which means that arsenic accelerates hydrogen entry. This appears to apply to the transient with a fluence of $1 \times 10^{17} / \mathrm{cm}^{2}$, where $\mathrm{P}_{\infty}, \mathrm{C}_{\mathrm{H}}$ and $\mathrm{D}_{\text {lag }}$ are larger than those of the un-implanted nickel, which is also supported from the results obtained by the etching. This implies that arsenic has an inhibiting effect of hydrogen evolution reaction; that is, the increase in the absorbed hydrogen due to the increase in the adsorbed hydrogen.

It is also recognized that the structure of the implanted layer for phosphorous and boron with a high fluence of more than $1 \times 10^{17} / \mathrm{cm}^{2}$ moves into the amorphous phase [10], which can apply to P- and B- implanted nickels with fluences of $1 \times 10^{17} / \mathrm{cm}^{2}$ and $3 \times 10^{17} / \mathrm{cm}^{2}$. In this case, $\mathrm{P}_{\infty}, \mathrm{C}_{\mathrm{H}}$ and $\mathrm{D}_{\text {lag }}$ are larger than those of the un-implanted nickel. This behavior is enhanced by the etching of a relatively short time, but disappears with a longer etching time. This suggests that the amorphous phase accelerates hydrogen entry, increases the number of the entry site or enhances hydrogen diffusion coefficient in the implanted layer. In contrast, in the case of S- implanted nickel with a fluence of 
$1 \times 10^{17} / \mathrm{cm}^{2}$, the decrease in $\mathrm{P}_{\infty}$, and $\mathrm{C}_{\mathrm{H}}$, but the increase in $\mathrm{D}_{\text {lag }}$ was observed, which is more evident by the etching. This may be explained by the structure change from austenite (fcc) to ferrite (bcc), since ferrite was much larger for $\mathrm{D}_{\text {lag }}$, but much smaller for $\mathrm{P}_{\infty}$ and $\mathrm{C}_{\mathrm{H}}$ than those of austenite.

\section{Conclusions}

The entry and transport of hydrogen in polycrystalline nickel implanted with various elements $(\mathrm{He}, \mathrm{Ar}, \mathrm{B}, \mathrm{P}, \mathrm{S}, \mathrm{Bi}, \mathrm{Ni}, \mathrm{Y}, \mathrm{Pt}, \mathrm{As}, \mathrm{Pb}$ and $\mathrm{Sb}$ ) were investigated in a fluence range of $1 \times 10^{14}$ to $2 \times 10^{17}$ ions $/ \mathrm{cm}^{2}$. The results obtained were summarized as follows:

(1) The effective diffusion coefficient of hydrogen and the effective solubility were dependent upon fluence and element in comparison to those obtained from un-implanted nickel.

(2) The entry of hydrogen was influenced by the elemental composition and structure/phase at the outermost surface of the implanted layer, but not inside the implanted layer; specifically in the case of Pt and As with the catalytic effect.

(3) On the other hand, the transport of hydrogen was mainly affected by gas bubbles and defects generated by implantation, the formation of the amorphous phase and so on in the implanted layer.

\section{References}

[1] R.M. Latanision and H. Opperhauser Jr., Metall. Trans. A, 5, pp. 483490, 1974.

[2] R.D. Kane and B.J. Berkowitz, Corrosion, 36, pp. 29- 36, 1980.

[3] R.H. Jones, S.M. Bruemmer, M.T. Thomas and D.R. Baer, Metall. Trans. A, 13, pp. 241- 249, 1982.

[4] A.W. Funkenbusch, L.A. Heldt and D.F. Stein, Metall. Trans. S, 13, pp. 611- 618, 1982.

[5] B.D. Craig, Metall. Trans. A, 15, pp. 565- 572, 1984.

[6] Y. Obino and T. Yamasaki, Metall. Trans. A, 15, pp. 519- 527, 1984.

[7] M.A Devanathan and Z. Stachurski, Proc. R. Soc. London, Ser. A, 270, pp. 90-102, 1962.

[8] F. Besenbacher, S.M Myers and J.K $>$ Norskov, Nucl. Instrum. Methods B, 7-8, pp. 55-63, 1985.

[9] R. Nishimura, RM. Latanision and G.K. Hubler, Materials Sci. and Engn., 90, pp. 243-251, 1987.

[10] Z.Y.A. Al-Tamimi, W.A. Grant and G. Carter, Nucl. Instr. and mech., 209/210, pp. 363-370, 1983. 